Pesq. Vet. Bras. 37(10):1159-1164, outubro 2017 DOI: $10.1590 / \mathrm{S} 0100-736 X 2017001000019$

\title{
Pesquisa de Mycoplasma em aves da família Psittacidae mantidas em diferentes cativeiros no Brasil Central ${ }^{1}$
}

\author{
Andréa M. Carvalho ${ }^{2 *}$, Maria A. Andrade 3 , Guido F.C. Linhares ${ }^{3}$ e Valéria S. Jaime ${ }^{3}$ \\ ABSTRACT.- Carvalho A.M., Andrade M.A., Linhares G.F.C. \& Jaime V.S. 2017. [Research of \\ Mycoplasma in the family Psittacidae kept in different captivities in Central Brazil.] \\ Pesquisa de Mycoplasma em aves da família Psittacidae mantidas em diferentes cativeiros \\ no Brasil Central. Pesquisa Veterinária Brasileira 37(10):1159-1164. Centro de Apoio ao De- \\ senvolvimento Tecnológico, Universidade de Brasília, Campus Universitário Darcy Ribeiro, \\ Brasília, DF 70904-970, Brazil. E-mail: andreavet.carvalho@yahoo.com.br \\ The study aimed to investigate the presence of Mycoplasma gallisepticum and M. syno- \\ viae in different species of captive parrots, in Central Brazil. A total of 300 samples were \\ collected from 41 brazilian species of Psittacidae at three captivities: Centro de Triagem \\ de Animais Silvestres (CETAS), a conservation and a commercial captivity. Fourteen spe- \\ cies presented positive samples for M. galisepticum, the most affected were blue-winged \\ macaw (Primolius maracana) (01/02, 50\%), blue-and-yellow macaw (Ara ararauna) \\ $(15 / 48,33.3 \%)$, and jandaia parakeet (Aratinga jandaia) $(03 / 10,30 \%)$. CETAS facility sho- \\ wed $21.62 \%(16 / 74)$ of positive samples, while the commercial captivity showed $15.7 \%$ \\ (19/121), and the conservation captivity 6.66\% (7/105). Only three species presented \\ positive samples for M. synoviae: blue-winged macaw (Primolius maracana) $(1 / 10,10 \%)$, \\ scarlet macaw (Ara macao) (1/12, 8.3\%) e blue-and-yellow macaw (Ara ararauna) $(2 / 48$, \\ 4.1\%). CETAS facility showed $2.7 \%(2 / 74)$ of positive samples, while the conservation \\ captivity presented $1.9 \%(2 / 105)$, and no positive samples were found in the commercial \\ captivity. Results showed a considerable number of positive samples for M. galisepticum in \\ species of Psittacidae family, indicating that these animals can be a silent source of infec- \\ tion for other birds, since they did not present clinical symptoms.
}

INDEX TERMS: Mycoplasma gallisepticum, Mycoplasma synoviae, Psittacidae, polymerase chain reaction (PCR).

RESUMO.- 0 presente estudo teve como objetivo investigar a presença de Mycoplasma gallisepticum e M. synoviae em diferentes espécies de psitacídeos cativos no Brasil Central. Um total de 300 amostras foram coletadas e corresponderam a 41 espécies de psitacídeos da fauna brasileira, provenientes do CETAS, criadouro comercial e criadouro conservacionista. Quatorze espécies apresentaram amostras positivas para M. gallisepticum destacando a maracanã-verdadeira (Primolius maracana) $(01 / 02,50 \%)$, a

\footnotetext{
${ }^{1}$ Recebido em 16 de julho de 2016.

Aceito para publicação em 20 de abril de 2017.

${ }^{2}$ Centro de Apoio ao Desenvolvimento Tecnológico (CDT), Universidade de Brasília, Campus Universitário Darcy Ribeiro, Edifício CDT, Caixa Postal 4397, Brasília, DF 70904-970, Brasil. *Autor para correspondência: andreavet.carvalho@yahoo.com.br

${ }^{3}$ Departamento de Medicina Veterinária Preventiva, Escola de Veterinária e Zootecnia, Universidade Federal de Goiás, Campus Samambaia, Rodov. Goiânia-Nova Veneza, Cx. Postal 131, Goiânia, GO 74001-970, Brasil.
}

arara-canindé (Ara ararauna) $(15 / 48,33,3 \%)$ e a jandaia-verdadeira (Aratinga jandaia) (03/10, 30\%). Amostras do CETAS obtiveram total de $21,62 \%(16 / 74)$ de amostras positivas, do criadouro comercial 15,7\% (19/121) e do criadouro conservacionista 6,66\% (7/105). Apenas três espécies foram positivas para M. synoviae sendo essas, a maracanã-pequena (Primolius maracana) (1/10 - 10\%), arara-macao (Ara macao) (1/12, 8,3\%) e arara-canindé (Ara ararauna) $(2 / 48,4,1 \%)$. O CETAS obteve $2,7 \%(2 / 74)$ de amostras positivas totais, enquanto o criadouro conservacionista obteve total de 1,9\% (2/105) de amostras. Não ocorreram amostras positivas para M. synoviae no criadouro comercial. Os resultados mostraram um considerável número de amostras positivas para $M$. gallisepticum em espécies da família Psittacidae, indicando que estes animais podem ser uma fonte de infecção silenciosa para outras aves, uma vez que não apresentaram sintomatologia clínica. 
TERMOS DE INDEXAÇ̃̃O: Mycoplasma gallisepticum, Mycoplasma synoviae, Psittacidae, reação em cadeia da polimerase (PCR).

\section{INTRODUCÃO}

O Brasil possui 1834 espécies já identificadas de aves, sendo que 160 encontram-se na "Lista das Espécies da Fauna Brasileira Ameaçadas de Extinção". A família Psittacidae possui 80 espécies no território nacional das quais 16 estão ameaçadas. São aves popularmente conhecidas e criadas em cativeiro, devido a sua beleza, variedade de plumagens e capacidade de imitar a voz humana (Pinho \& Nogueira 2000). Dentre as diferentes ferramentas que podem ser utilizadas para a conservação de espécies silvestres destaca-se a investigação de doenças infecciosas, através do estado sanitário de animais e o controle sanitário em criatórios e vida livre (Deem et al. 2001, Saidenberg et al. 2012). A pesquisa do estado clínico de aves é importante para a obtenção de dados sanitários e utilização dessas informações como ferramenta de auxílio na manutenção das espécies. Visando impedir surtos de doenças, contaminação de ambientes naturais, declínio de populações ou ainda a extinção de espécies (Daszak et al. 2004).

Psitacídeos cativos são acometidos por uma variedade de enfermidades provocadas por agentes infecciosos. 0 gênero Mycoplasma possui cerca de 100 espécies das quais vinte já foram isoladas em aves, sendo as espécies $\mathrm{Myco-}$ plasma gallisepticum, M. synoviae, M. meleagridis e M. iowae as mais patogênicas A micoplasmose se manifesta na forma clínica e assintomática. Sua disseminação ocorre principalmente por meio de aerossóis, contágio indireto com outras aves ou ainda por meio de pessoas, outros animais, ração, água e fômites. Além da via venérea por meio do acasalamento ou inseminação artificial (Stipkovits \& Kempft 1996, Nascimento \& Pereira 2009).

A micoplasmose é mais frequente em pássaros e pombos, sendo relatada como agente de conjuntivite em mais de vinte espécies de passeriformes (Farmer et al. 2005). Essas aves desenvolvem sinais de conjuntivite unilateral ou bilateral acompanhada ou não de aumento do seio infraorbital (Phalen et al. 2006). 0 passeriforme Carpodacus mexicanus foi considerado responsável pela disseminação de Mycoplasma gallisepticum nos Estados Unidos (Fischer et al. 1997), provocando contaminação no ambiente natural e outras aves (Farmer et al. 2005). Poveda et al. (1990) isolaram Mycoplasma gypis de abutres, enquanto Oaks et al. (2004) isolaram e identificaram subespécies de $M$. vulturii em abutre branco (Gypsben galensis). Mycoplasma gallinarum, $M$. gallinaceume $M$. iners já foram isolados em doença respiratória em falcão (Falco peregrinus) (Poveda et al. 1990) e a espécie $M$. corogypsi já foi encontrada causando lesão podal em urubu (Coragy psatratus) (Panangala et al. 1993).

Uma vez infectados, psitacídeos podem desenvolver a micoplasmose clínica, porém frequentemente se tornam portadores assintomáticos, onde desempenham importante papel na disseminação do agente (Phalen et al. 2006). Embora psitacídeos desenvolvam frequentemente sinusite e conjuntivite, não são hospedeiros comuns e a patogenicidade de Mycoplasma nessas aves não está bem elucidada (Phalen et al. 2006, Buim et al. 2009). Consequentemente é importante sua investigação, já que a ave se torna portadora e imunossuprimida (Bradbury et al. 1993), favorecendo ainda, o acometimento por outras enfermidades.

Essa pesquisa teve como objetivo a investigação das bactérias Mycoplasma gallisepticum e M. synoviae pela técnica da reação em cadeia da polimerase em espécies da família Psittacidae de ocorrência no território nacional e mantidas em três cativeiros diferentes no Brasil Central.

\section{MATERIAL E MÉTODOS}

As amostras foram coletadas em aves da família Psittacidae mantidas em cativeiro, em três locais diferentes no Brasil Central. Foi investigado o Centro de Triagem de Animais Silvestres (CETAS-G0), um criadouro conservacionista, localizado no município de Nova Crixás-GO e um criadouro comercial na zona rural de Nazário-GO, ambos registrados pelo Instituto Brasileiro de Meio Ambiente (IBAMA). As análises foram realizadas no Laboratório de Diagnóstico Molecular, Departamento de Medicina Veterinária da Escola de Veterinária e Zootecnia (EVZ) da Universidade Federal de Goiás (UFG). 0 projeto foi pré-avaliado e aprovado pela Comissão de Ética da UFG, sob protocolo de número 001/11.

A coleta de material biológico foi realizada em 300 aves de diferentes espécies de psitacídeos, aproximadamente 30\% do total da população por espécie em cada criação. Foram coletadas 74 , 121 e 105 amostras, no CETAS, criadouro comercial e criadouro conservacionista, respectivamente. A arara-canindé (Ara ararauna) $(48 / 300,16 \%)$ foi à espécie com maior número de amostras coletadas. Seguida do papagaio-verdadeiro (Amazona aestiva) $(47 / 300,15,6 \%)$, papagaio do mangue (Amazona amazonica) $(19 / 300,6,3 \%)$, periquito do encontro amarelo (Brotogeris chiriri) $(17 / 300,5,6 \%)$, periquitão-maracanã (Aratinga leocophtalmos) $(17 / 300,5,6 \%)$, arara-macao (Ara macao) $(12 / 300,4 \%)$, jandaia-estrela (Aratinga aurea) (11/300, 3,6\%), arara-vermelha (Ara cloropthera) (10/300, 3,3\%), maracanã-pequena (Diopcitaca nobilies) (10/300, 3,3\%), jandaia da testa vermelha (Aratinga auricaphilus) (08/300, 2,6\%) e arara-azul (Anodorhynchus hyacinthinus) $(07 / 300,2,3 \%)$. As demais espécies com material coletado tiveram amostras de cinco ou menos indivíduos (Quadro 1).

As aves foram capturadas com puçá e dispostas com o ventre para cima, com o corpo levemente inclinado. Com uso de luvas de procedimento, um suabe previamente embebido em solução salina a $0,85 \%$ foi introduzido na coana e orofaringe da ave. Após coleta os suabes foram acondicionados em tubos Eppendorfs esterilizados e mantidos sob refrigeração até o transporte para o laboratório, onde foram armazenados a temperatura de $-20^{\circ} \mathrm{C} \mathrm{em}$ freezer e posteriormente processados pela técnica da reação em cadeia da polimerase (PCR).

O protocolo seguido para a PCR foi o proposto por Lauerman (1995). Após o descongelamento, as amostras foram acrescidas de $1 \mathrm{~mL}$ de água-ultra pura e foram imergidas e mantidas em banho-maria com água fervente por 10 minutos, seguido de resfriamento a $-20^{\circ} \mathrm{C}$ por mais dez minutos e então centrifugadas a $14.000 \mathrm{~g}$ por cinco minutos.

As sequências dos oligonucleotídeos utilizados para $\mathrm{Myco-}$ plasma gallisepticum foram: M. gallisepticum-14 (5'-GAGCTAATCTGTAAAGTTGGTC- 3') e M. gallisepticum-13 (5'-GCTTCCTTGCGCTTAGCAAC- 3'). 0 produto amplificado é de 180 pares de bases (pb). Para Mycoplasma synoviae foram utilizados os seguintes oligonucleotídeos: M. synoviae forward (5'-GAGAAGCAAAATAGTGATATCA- 3') e $M$. synoviae reverse (5'-CAGTCGTCTCCGAAGTTAACAA- 3') que amplificam um produto de 211 pares de bases (pb). Para cada $5 \mu \mathrm{L}$ de amostra foram preparados $45 \mu \mathrm{L}$ do mix para

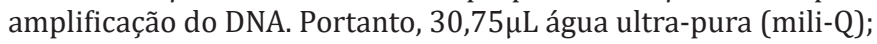


Quadro 1. Número de espécies de psitacídeos coletados por cativeiro (CETAS, CM-criadouro comercial e CV-criadouro conservacionista) total e percentual de amostras coletadas por cativeiro

\begin{tabular}{|c|c|c|c|c|c|}
\hline Espécies & CETAS & $\mathrm{CM}$ & $\mathrm{CV}$ & Total & $\%$ \\
\hline Ara ararauna (Linnaeus, 1758) & 30 & 11 & 07 & 48 & $16 \%$ \\
\hline Ara chloropterus (Gray, 1859) & - & 04 & 06 & 10 & $0,33 \%$ \\
\hline Ara macao (Linnaeus, 1758) & - & 06 & 06 & 12 & $4 \%$ \\
\hline $\begin{array}{l}\text { Anodorhynchus hyacinthinus } \\
\text { (Latham, 1790) }\end{array}$ & - & 02 & 05 & 07 & $2,3 \%$ \\
\hline Amazona amazonica (Linnaeus, 1766) & 01 & 14 & 04 & 19 & $6,3 \%$ \\
\hline Amazona aestiva (Linnaeus, 1758) & 13 & 32 & 02 & 47 & $15,6 \%$ \\
\hline Amazona farinosa (Boddaert, 17 & - & 01 & 03 & 04 & $1,3 \%$ \\
\hline Amazona brasilien. & - & - & 02 & 02 & $0,6 \%$ \\
\hline Amazona vinacea & - & - & 01 & 01 & $0,3 \%$ \\
\hline Amazona festiva (Linnaeus, 1758) & - & - & 01 & 01 & $0,3 \%$ \\
\hline Amazona ochrocephala (Gmelin, & - & 03 & 01 & 04 & $1,3 \%$ \\
\hline & - & - & 02 & 02 & $0,6 \%$ \\
\hline Pion & 01 & 03 & 01 & 05 & $1,6 \%$ \\
\hline & - & 01 & 2 & 03 & $1 \%$ \\
\hline & & 02 & 1 & 04 & $1,3 \%$ \\
\hline & & 0 & 2 & 08 & $2,6 \%$ \\
\hline & & 06 & 02 & 11 & $3,6 \%$ \\
\hline & - & 03 & - & 03 & $1 \%$ \\
\hline $\begin{array}{l}\text { Arating } \\
\text { (Statius }\end{array}$ & 09 & 07 & 01 & 17 & $5,6 \%$ \\
\hline & - & 03 & & 05 & $1,6 \%$ \\
\hline$A$ & - & - & 0 & 01 & $0,3 \%$ \\
\hline & - & 05 & 0 & 10 & $3,3 \%$ \\
\hline & - & 02 & 0 & 04 & $1,3 \%$ \\
\hline & - & 01 & 0 & 03 & $1 \%$ \\
\hline & - & 01 & & 03 & $1 \%$ \\
\hline & - & & & 02 & $0,6 \%$ \\
\hline & 01 & 03 & 06 & 10 & $3,3 \%$ \\
\hline & 14 & 03 & - & 17 & $5,6 \%$ \\
\hline & - & 03 & - & 03 & $1 \%$ \\
\hline & - & - & 01 & 01 & $0,3 \%$ \\
\hline & - & - & 01 & 01 & $0,3 \%$ \\
\hline aster (Kuhl, 1820) & - & - & 03 & 03 & $1 \%$ \\
\hline phalus (Linnaeus, 1758) & - & - & 02 & 02 & $0,6 \%$ \\
\hline Graydidascalus brachyurus (Kuhl, 1820) & - & - & 01 & 01 & $0,3 \%$ \\
\hline Pyrrhura pfrimeri Miranda-Ribeiro, 1920 & - & - & 16 & 16 & $5,3 \%$ \\
\hline Pyrrhura cruentata (Wied, 1820) & - & - & 02 & 02 & $0,6 \%$ \\
\hline Pyrrhura picta (Statius Muller, 1776) & - & - & 02 & 02 & $0,6 \%$ \\
\hline Pyrrhura leucotis (Kuhl, 1820) & - & - & 03 & 03 & $1 \%$ \\
\hline Pyrrhura perlata (Spix, 1824) & - & & 03 & 03 & $0,9 \%$ \\
\hline
\end{tabular}

5,00 $\mu \mathrm{L}$ 10x solução tampão (Buffer 10x reaction); 1,00 $\mu \mathrm{L}$ base nitrogenada dATP $(10 \mathrm{mM}) ; 1,00 \mu \mathrm{L}$ base nitrogenada dCTP(10mM); $1,00 \mu \mathrm{L}$ base nitrogenada dGTP( $10 \mathrm{mN}) ; 1.00 \mu \mathrm{L}$ base nitrogenada dTTP $(10 \mathrm{mN}) ; 0,50 \mu \mathrm{Lprimer} F(20 \mathrm{pMol} / \mu \mathrm{L}) ; 0,50 \mu \mathrm{L}$ primer $\mathrm{R}$ $(20 \mathrm{pMol} / \mu \mathrm{L}) ; 0,25 \mu \mathrm{lTaq}$ polimerase DNA; 4,00 $\mu \mathrm{L}$ M. gallisepticum $\mathrm{MgCl} 2$ (50nM) (Lauerman 1995). Após preparar $45 \mu \mathrm{L}$ do mix de amplificação do DNA e adicionar $5 \mu \mathrm{L}$ da amostra estas foram levadas ao termociclador, programado com uma sequência de 40 ciclos na temperaturas e tempos de $94^{\circ} \mathrm{C}$ por 30 segundos, $55^{\circ} \mathrm{C}$ por 30 segundos e $72^{\circ} \mathrm{C}$ por mais 60 segundos. Após o último ciclo a reação foi finalizada com um período extra de extensão de 5 minutos a $72^{\circ} \mathrm{C}$.

Posteriormente a amplificação, as amostras foram aplicadas em gel de agarose a 1,2\% corado com brometo de etídio $(0,5 \mu \mathrm{g} /$ $\mathrm{mL}$ ) por imersão em solução a $0,4 \mathrm{mg} / \mathrm{mL}$. As amostras foram submetidas à eletroforese a $80 \mathrm{v}$ por 1 a 2 horas e as bandas visualizadas e analisadas com auxílio de um trans-iluminador UV. Para a determinação do tamanho dos fragmentos amplificados, foi utilizado, para cada corrida de eletroforese, $5 \mathrm{mg}$ de marcador de peso molecular de 100pb (in-vitrogen). Os resultados foram cap- turados e gravados utilizando o sistema de imagem digital (Doc Print, VilberLourmat).

Os resultados foram comparados quanto à frequência de aves positivas, por espécie e local de coleta. Através do teste Exato de Fisher foram analisadas ainda, as diferenças entre as frequências de amostras positivas a Mycoplasma gallisepticum e Mycoplasma synoviae dos diferentes locais de coleta, sendo que foram feitas análises separadas entre CETAS e criadouros, CETAS e criadouro comercial, CETAS e criadouro conservacionista, e criadouro comercial e criadouro conservacionista. As análises foram feitas no QuickCalcs - Online Calculators for Scientists (Graphpad Software 2012), adotando-se como nível de significância de 5 \%.

\section{RESULTADOS E DISCUSSÃO}

O número e o percentual de amostras positivas aos $\mathrm{Myco-}$ plasma gallisepticum e M. synoviae nos psitacídeos examinados, estão registrados nos Quadros 2 e 3. Pela sua análise, depreende-se que houve positividade em 14 espécies das 41 avaliadas para M. gallisepticum e (34,15\%) e três para M. synoviae $(7,32 \%)$. Observou-se que durante a contenção e a coleta de amostras, as aves não manifestaram nenhum sinal de conjuntivite, edema periocular, rinite, descarga nasal e ocular sugestivo de micoplasmose, sinais frequentemente identificados em aves silvestres com micoplasmose (Dhondt et al. 2007). De acordo com Lecis et al. (2010) micoplasmas possuem diferentes graus de patogenicidade e prevalência. Como no presente estudo não foi observado sintomatologia clínica nas aves sugere-se que um dos fatores que possa ter contribuído para a infecção inaparente seja a presença de cepas de baixa patogenicidade.

$\mathrm{Na}$ espécie Ara ararauna obteve-se alta frequência (31\%, 15/48) (Quadro 2) para a presença de Mycoplasma gallisepticum, corroborando com pesquisa realizada por Gomes et al. (2010). Os autores avaliaram pela técnica de PCR a presença de M. gallisepticum em 140 amostras de suabes coletados na fenda palatina, traqueia e cloaca de psitacídeos mortos em Belo-Horizonte. Detectaram A. ararauna com o maior percentual de amostras positivas (80\%). Além da positividade da $A$. ararauna para $M$. gallisepticum esta foi a espécie com maior número de amostras positivas para M. synoviae. Uma possível explicação para as altas frequências deste patógeno em araras-canindé seria a alta população cativa e contato entre as aves em cativeiros, facilitando a transmissão direta e indireta de micoplasmas.

Os papagaios apresentaram frequências para Mycoplasma gallisepticum de 14\% (Amazona aestiva), 21\% (Amazona amazonica), e 25\% (Alipiopsita xanthops e Amazona ochrocephala) (Quadro 2). Tais resultados também são semelhantes aos resultados de Gomes et al. (2010), que encontraram 52,5\% de amostras positivas em Amazona aestiva e 50\% em Amazona amazonica. Pode-se dizer que esses resultados estão de acordo com o esperado, uma vez que, araras e papagaios se situam entre as espécies de psitacídeos mais populares e frequentemente comercializadas (Pinho \& Nogueira 2000).

Sugere-se que a alta frequência observada, para a presença de Mycoplasma gallisepticum, nas outras espécies menos comercializadas, como Primolius maracana (50\%), Aratinga jandaia (30\%), Guarouba guarouba (25\%), Aratinga nenday (20\%), Aratinga aurea (18\%) (Quadro 2). 
Quadro 2. Número e percentual de aves da família Psittacidae positivas para a pesquisa de Mycoplasma gallisepticum pela reação em cadeia da polimerase (PCR) por cativeiro (CETAS; CM - criadouro comercial; CV - criadouro conservacionista)

\begin{tabular}{|c|c|c|c|c|c|c|c|}
\hline \multirow[t]{2}{*}{ Nome popular } & \multirow[t]{2}{*}{ Espécie } & \multirow[t]{2}{*}{ CETAS } & \multirow[t]{2}{*}{$\mathrm{CM}$} & \multirow[t]{2}{*}{$\mathrm{CV}$} & \multicolumn{2}{|c|}{ Total } & \multirow[t]{2}{*}{$\%$} \\
\hline & & & & & Positivas & Aves & \\
\hline Arara-canindé & Ara ararauna & 10 & 05 & - & 15 & 48 & $32, \%$ \\
\hline Arara-vermelha & Ara cloropthera & - & 01 & - & 01 & 10 & $10 \%$ \\
\hline Arara-macao & Ara macao & - & 01 & - & 01 & 12 & $8,33 \%$ \\
\hline Papagaio do mangue & Amazona amazonica & 01 & 03 & - & 04 & 19 & $21 \%$ \\
\hline Papagaio-verdadeiro & Amazona aestiva & 03 & 04 & - & 07 & 47 & $14,89 \%$ \\
\hline Papagaio-campeiro & Amazona ochrocephala & - & 01 & - & 01 & 04 & $25 \%$ \\
\hline Papagaio-galego & Alipiopsita xanthops & - & 01 & - & 01 & 04 & $25 \%$ \\
\hline Jandaia-estrela & Aratinga aurea & 01 & 01 & - & 02 & 11 & $18,18 \%$ \\
\hline Príncipe-negro & Aratinga nenday & - & - & 01 & 01 & 05 & $20 \%$ \\
\hline Jandaia-verdadeira & Aratinga jandaia & - & - & 03 & 03 & 10 & $30 \%$ \\
\hline Ararajuba & Guarouba guarouba & - & 01 & - & 01 & 04 & $25 \%$ \\
\hline Maracanã-verdadeira & Primolius maracana & - & - & 01 & 01 & 02 & $50 \%$ \\
\hline Maracanã-pequena & Diopcitaca nobilies & - & - & 01 & 01 & 10 & $10 \%$ \\
\hline Periquito do encontro amarelo & Brotogeris chiriri & 01 & 01 & - & 02 & 17 & $11,76 \%$ \\
\hline
\end{tabular}

Quadro 3. Número e percentual de aves da família Psittacidae positivas para a pesquisa de Mycoplasma synoviae pela reação em cadeia da polimerase (PCR) por cativeiro (CETAS; CM - criadouro comercial; CV - criadouro conservacionista)

\begin{tabular}{lccccccc}
\hline Nome popular & Espécie & CETAS & CM & CV & \multicolumn{2}{c}{ Total } & Aves \\
\cline { 5 - 6 } & & & & & Positivas & Aves \\
Arara-canindé & Ara ararauna & 02 & - & - & 02 & 48 & $4,16 \%$ \\
Arara-macao & Ara macao & - & - & 01 & 01 & 12 & $8,3 \%$ \\
Maracanã-pequena & Diopcitaca nobilies & - & - & 01 & 01 & 10 & $10 \%$
\end{tabular}

Bem como a elevada presença da bactéria encontrada por Gomes et al. (2010) nas espécies Pionus fuscus (60\%) e Aratinga jandaya (50\%). Provavelmente esteja relacionada ao caráter dispersivo do patógeno (Fischer et al. 1997) e demonstra a amplitude de possíveis espécies de aves que podem ser hospedeiras do M. gallisepticum, como proposto por Lierz et al. (2008).

No presente estudo, as aves maracanã-pequena (Primolius maracana), arara-macao (Ara macao) e arara-canindé (Ara ararauna) foram positivas em 10\%, 8,3\% e 4,1\% para Mycoplasma synoviae, respectivamente (Quadro 3). Somente uma, Primolius maracana, apresentou positividade para as duas espécies estudadas. Relatos na literatura da presença de $M$. synoviae em psitaciformes são raros. Entretanto já foram descritos em outras aves silvestres como pinguins (Bencina et al. 1987), em Passer domesticus (Poveda et al. 1990); em anseriformes (Tiong 1990) e na espécie de urubu Gyps fulvus (Lecis et al. 2010). Pode-se dizer que assim como outras espécies de Mycoplasma, o M. synoviae também é capaz de infectar diversas famílias e espécies de aves. Conclui-se mediante os resultados encontrados neste estudo e pela escassez de dados na literatura sobre a infecção por $M$. synoviae em psitacídeos, que sua ocorrência nestas aves é baixa e por isto, não tem a mesma casuística clínica que a espécie M. gallisepticum.

A presença de Mycoplasma gallisepticum estudada por cativeiro foi alta, no CETAS e no criadouro comercial, $21,62 \%(16 / 74)$ e $15,70 \%$ (19/121), respectivamente. Por outro lado o criadouro conservacionista teve um resultado significativamente menor, com 6,66\% (7/105) de amostras positivas. Para a presença de $M$. synoviae não ocorreram amostras positivas no criadouro comercial $(0 / 121,0,0 \%)$, o que diferiu do criadouro conservacionista $(2 / 105,1,9 \%)$ e do CETAS $(2 / 74,2,7 \%)$ onde embora tenha sido baixa a ocorrência a bactéria foi detectada (Figura 1). A alta presença de aves infectadas no CETAS e criadouro comercial pela espécie $M$. gallisepticum admite que estes locais estiveram com alta contaminação. Contudo, a ausência de aves infectadas para a espécie $M$. synoviae no criadouro comercial e os resultados obtidos nos outros dois estabelecimentos, pode estar relacionada a uma baixa presença desta bactéria, quando comparado à presença de M. gallisepticum.

A alta ocorrência de aves positivas encontrada no CETAS pode estar relacionada com as características do próprio recinto ou do ambiente em que se encontram. Neste local ocorre contato direto e indireto de psitacídeos com aves potencialmente portadoras de Mycoplasma como os passeriformes. Ressalta-se que, de acordo com Nascimento \& Pereira (2009), a transmissão de micoplasmas ocorre geralmente entre espécies de hospedeiros estreitamente relacionados. Acrescenta-se ainda que a bactéria possa compor a microbiota normal de passeriformes, que estão em constante eliminação do patógeno (Farmer et al. 2005). De acordo com Kleven \& Fletcher (1983), a proximidade de gaiolas ou viveiros de passeriformes com viveiros de psitacídeos, pode favorecer ou predispor as infecções, assim como a presença de aves de vida livre, como os pardais, que são considerados dispersores destes agentes. Por tanto, a presença dessas aves e a ocorrência de contaminação cruzada implicam no aumento significativo de psitacídeos positivos para M. gallisepticum.

De acordo com a análise estatística pelo Teste Exato de Fischer, o número de animais infectados, entre CETAS e o criadouro comercial, não apresentou diferença significativa 


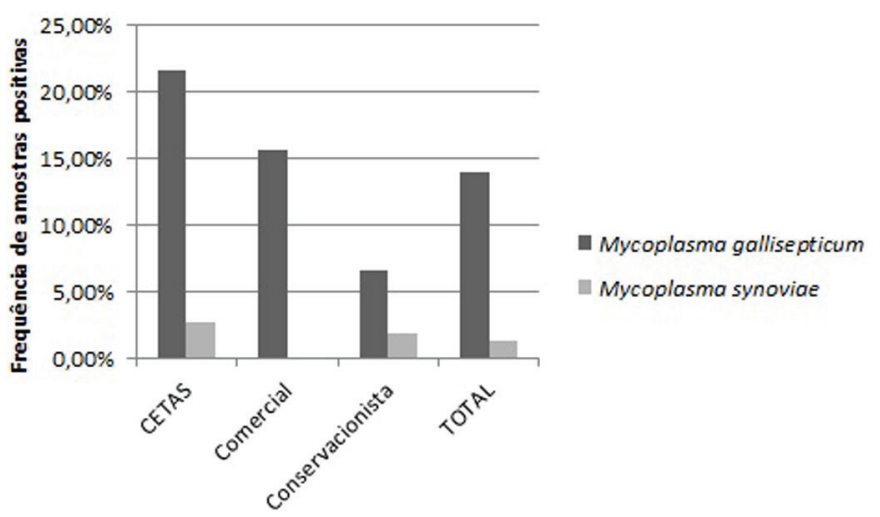

Fig.1. Frequência e total de amostras positivas nos três estabelecimentos estudados para a presença de Mycoplasma gallisepticum e Mycoplasma synoviae em aves da família Psittacidae.

Quadro 4. Número de aves da família Psittacidae infectadas e não infectadas por Mycoplasma gallisepticum em cada criadouro, com o valor de p (Teste Exato de Fischer) para cada comparação realizada

\begin{tabular}{lccc}
\hline Criadouros & \multicolumn{2}{c}{ Aves examinadas } & \multirow{2}{*}{ p-valor* } \\
\cline { 2 - 3 } & Não infectadas & Infectadas & \\
\hline CETAS & 58 & 16 & $=0.3381$ \\
Comercial & 102 & 19 & \\
CETAS & 58 & 16 & $=0.0055^{*}$ \\
Conservacionista & 98 & 07 & \\
CETAS & 58 & 16 & $=0.0348^{*}$ \\
Conservacionista e Comercial & 200 & 26 & \\
Comercial & 102 & 19 & $=0.0388^{*}$ \\
Conservacionista & 98 & 07 &
\end{tabular}

* Valor de p significativo (nível de significância de 5\%).

Quadro 5. Número de aves da família Psittacidae infectadas e não infectadas por Mycoplasma synoviae em cada criadouro, com o valor de p (Teste Exato de Fischer) para cada comparação realizada

\begin{tabular}{lccl}
\hline Criadouros & \multicolumn{2}{c}{ Aves examinadas } & p-valor* \\
\cline { 2 - 3 } & Não infectadas & Infectadas & \\
\hline CETAS & 72 & 02 & $=0.1428$ \\
Comercial & 121 & 00 & \\
CETAS & 72 & 02 & $=1.0000$ \\
Conservacionista & 103 & 02 & \\
CETAS & 72 & 02 & $=0.2554$ \\
Conservacionista e comercial & 224 & 02 & \\
Comercial & 121 & 00 & $=0.2147$ \\
Conservacionista & 103 & 02 &
\end{tabular}

* Valor de p significativo (nível de significância de 5\%).

para as amostras de Mycoplasma gallisepticum. Entretanto, ocorreu diferença significativa entre as amostras positivas do CETAS e as do criadouro conservacionista, e ainda entre o CETAS e os dois criadouros combinados e por último entre o criadouro comercial e o criadouro conservacionista (Quadro 4). Para a presença de Mycoplasma synoviae não houve diferença significativa entre os resultados encontrados, possivelmente devido à baixa frequência do patógeno nas criações analisadas (Quadro 5).

A diferença encontrada entre o CETAS e os dois criadouros combinados para a presença de Mycoplasma gallisepticum, provavelmente é devido à alta ocorrência de amostras positivas no criadouro comercial, uma vez que a comparação CETAS e criadouro comercial não tenha sido significativa. Medidas de biossegurança como a boa higiene e o manejo adequado diminuem a incidência de micoplasmas em uma criação (Nascimento \& Pereira 2009). Contudo, a baixa ocorrência de $M$. gallisepticum no criadouro conservacionista $(6,66 \%)$ pode estar relacionada a um manejo sanitário satisfatório, bem como uma baixa densidade de aves dentro do mesmo recinto, como foi observado durante a coleta. Se tratando ainda de uma criação conservacionista, espera-se que esta tenha menor risco de infecções cruzadas, visto que difere significativamente na casuística de entrada e saída de aves quando comparada a um CETAS ou criatórios comerciais, e por tanto, diminui possibilidades de introdução de aves portadoras no plantel e instalações de infecções.

Os resultados obtidos mostraram que o criadouro conservacionista, por suas qualidades de recinto e baixa contaminação cruzada é um local adequado para a preservação de aves silvestres. Pode-se dizer que os dados do presente estudo estão de acordo com o trabalho de Mattes et al. (2005), onde a colonização intestinal por Escherichia coli foi comparada em dois cativeiros diferentes. A presença da bactéria foi significativamente maior no criadouro recreacionista $(80 \%, 28 / 35)$ quando comparado ao conservacionista $(20 \%, 10 / 50)$. Por tanto, criatórios conservacionistas contribuem de forma mais efetiva com a preservação e manutenção das espécies em cativeiro, quando comparada a saúde das aves dos outros locais estudados.

A fonte primária de infecção para micoplasmas é o hospedeiro infectado, ou melhor, um portador inaparente. Por isso é importante que se investigue a presença de micoplasmas em aves recém-chegadas ao plantel, visto que a introdução de novas aves em um criadouro contribuirá para a disseminação e manutenção do agente dentro de uma população animal. Além disso, um ponto fundamental para criações cativas de aves silvestres é reduzir a presença de agentes patogênicos e evitar sua reinstalação. Para tanto, deve-se impedir a proximidade de aves de diferentes famílias dentro de um mesmo estabelecimento, adotando medidas de biossegurança, realizando exames para estabelecer diagnósticos e programas de quarentena. As aves do plantel devem ser examinadas e tratadas corretamente apresentando infecção clínica ou subclínica para erradicar a presença de espécies de micoplamas em criações de psitacídeos. Dessa maneira, considera-se que a baixa ocorrência de patógenos em aves cativas, possa auxiliar na preservação das mesmas, bem como de outras espécies de vida livre e na saúde do ambiente natural, devido à redução da disseminação de agentes infecciosos.

Agradecimentos.- À Coordenação de Aperfeiçoamento de Pessoal de Nível Superior (CAPES) pela bolsa de pesquisa concedida a primeira autora. Ao Laboratório de Diagnóstico Molecular, Departamento de Medicina Veterinária da Escola de Veterinária e Zootecnia (EVZ/UFG). Ao Centro de triagem de animais silvestres (CETAS) e aos proprietários dos criadouros de aves, pelo acesso e ajuda na coleta do material clínico das aves.

\section{REFERÊNCIAS}

Bencina D., Dorrer D. \& Tadina T. 1987. Mycoplasma species isolated from six avian species. Avian Pathol. 16:653-664. 
Bradbury J.M., Abdul-Wahab O.M.S., Yavari C.A., Dupiellet J.P. \& Bov'e J.M. 1993. Mycoplasma imitans sp. nov. in related to Mycoplasma gallisepticum and found in birds. Int. J. Syst. Bacteriol. 43(4):721-728.

Buim M.R., Mettifogo E., Timenetsky J., Kleven S. \& Ferreira A.J.P. 2009. Epidemiological survey on Mycoplasma gallisepticum and M. synoviae by multiplex PCR in commercial poultry. Pesq. Vet. Bras. 29(7):552556.

Daszak P., Tabor G.M., Kilpatrick A.M., Epstein J. \& Plowright R. 2004. Conservation Medicine and a new agenda for emerging disease. Ann. N.Y. Acad. Sci. 1026:1-11.

Deem S.L., Karesh W.B. \& Weisman W. 2001. Putting theory into practice: wildlife health in conservation. Conserv. Biol. 15(5):1224-1233.

Dhondt K.V., Dhondt A.A. \& Ley D.H. 2007. Effects of route of inoculation on Mycoplasma gallisepticum infection in captive house finches. Avian Pathol. 36(6):475-479.

Farmer K.L., Hill G.E. \& Roberts S.R. 2005. Susceptibility of wild songbirds to the house finch strain of Mycoplasma gallisepticum. J. Wildlife Dis. 42(2):317-325.

Fischer J.R., Stallknecht D.E., Luttrell P., Dhondt A.A. \& Converse K.A. 1997. Mycoplasmal conjunctivitis in wild songbirds: the spread of a new contagious disease in a mobile host population. Emerg. Infect. Dis. 3:69-72.

Gomes A.M., Costa L.L., Vilela D.A.R., Marques M.V.R., Carvalhaes A.G., Marin S.Y., Costa M.P., Horta R.S., Resende J.S. \& Martins N.R.S. 2010. Detection of Mycoplasma gallisepticum in dead captive Psittacines in Belo Horizonte, Brazil. Revta Bras. Ciênc. Avic. 12(2):75-78.

Graphpad Software [Online] Calculators for Scientists. Disponível em <http://www.graphpad.com/quickcalcs/contingency1.cfm> Acesso em 22 jan. 2012.

Kleven S.H. \& Fletcher D.J. 1983. Laboratory infection of hause sparrows (Passer domesticus) with Mycoplasma gallisepticum and Mycoplasma synoviae. Avian Dis. 27:308-311.

Lauerman L.H. 1995. Avian mycoplasma identification ising polymerase chain reaction amplicon and restriction fragment length polymorphism analysis. Avian Dis. 39:804-811.

Lecis R., Chessa B., Cacciotto C., Addis M.F., Coradduzza E., Berlinguer F., Muzzeddu M., Lierz M., Carcangiu L., Pittau M. \& Alberti A. 2010. Identi- fication and characterization of novel Micoplasmas spp. belonging to the hominis group from griffon vultures. Res. Vet. Sci. 89:58-64.

Lierz M., Hagen N., Hernadez-Divers S.J. \& Hafez H.M. 2008. Occurrence of Mycoplasmas In free-ranging birds of prey in Germany. J. Wildlife Dis. 44 (4):845-850.

Mattes B.R., Consiglio S. de A.S., Almeida B.Z., Guido M.C., Orsi R.B., Silva R.M., Costa A., Ferreira A.J.P. \& Knobl T. 2005. Influência da biossegurança na colonização intestinal por Escherichia coli em psitacídeos. Arqs Inst. Biológico, São Paulo, 72(1):13-16.

Nascimento E.R. \& Pereira V.L.A. 2009. Micoplasmoses, p.485-495. In: Berchieri Jr A., Silva E.N., Di Fábio J., Sesti L. \& Zuanaze M.A.F. (Eds), Doenças das Aves. $2^{\underline{a}}$ ed. Ed. Facta, Fundação de APINCO de Ciência e Tecnologia Avícolas, Campinas, SP.

Oaks J.L., Donahoe S.L., Rurangirwa F.R., Rideout B.A., Gilbert M. \& Virani M.Z. 2004. Identification of a novel Mycoplasma species from an oriental white backed vulture (Gyps bengalensis). J. Clin. Microbiol. 42(12):59095912.

Panangala V.S., Stringfellow J.S., Dybvig K., Woodard A., Sun F., Rose L. \& Gresham M.M. 1993. Mycoplasma corogypsi sp. nov., a new species from the footpad abscess of a black vulture, Coragyps atratus. Int. J. Syst. Bacteriol. 43:585-590.

Phalen D.N., Logan K.S. \& Snowden K.F. 2006. Encephalitozoon bellem infection as the cause of a unilateral chronic keratoconjunctivitis in an umbrella cockatoo (Cacatua alba). Vet. Ophthalmol. 9(1):59-63.

Pinho J.B. \& Nogueira F.M.B. 2000. Mostra da retirada de psitacídeos em cativeiro na cidade de Cuiabá e Pantanal de Poconé, Mato Grosso, no período 1995-1997. Ararajuba 8(1):51-53.

Poveda J.B., Carranza J., Miranda A., Garrido A., Hermoso M., Fernandez A. \& Domenech J. 1990. An epizootiological study of avian mycoplasmas in Southern Spain. Avian Pathol. 19:627-633.

Saidenberg A.B., Teixeira R.H.F., Guedes N.M.R., Allgayer M.C., Melville P.A. \& Benites N.R. 2012. Molecular detection of enteropathogenic Escherichia coli in asymptomatic captive psittacines. Pesq. Vet. Bras. 32(9):922-962.

Stipkovits L. \& Kempft I. 1996. Mycoplasmosis in poultry. Rev. Sci. Tech. Off. Int. Épiz. 15(4):1495-1525.

Tiong S.K. 1990. Mycoplasmas and Acholeplasmas isolated from ducks and their possible association with pasteurellas. Vet. Rec. 127:64-66. 